\title{
Article \\ Pandemic Stress and Its Correlates among Pregnant Women during the Second Wave of COVID-19 in Poland
}

\author{
Michalina Ilska ${ }^{1, * \mathbb{C}}$, Anna Kołodziej-Zaleska ${ }^{1}$, Anna Brandt-Salmeri ${ }^{1}$, Heidi Preis ${ }^{2}$ and Marci Lobel ${ }^{2}$ \\ 1 Institute of Psychology, University of Silesia in Katowice, Grażyńskiego Street 53, 40-126 Katowice, Poland; \\ anna.kolodziej-zaleska@us.edu.pl (A.K.-Z.); anna.brandt-salmeri@us.edu.pl (A.B.-S.) \\ 2 Department of Psychology, Stony Brook University, Stony Brook, NY 11794, USA; \\ heidi.preis@stonybrook.edu (H.P.); marci.lobel@stonybrook.edu (M.L.) \\ * Correspondence: michalina.ilska@us.edu.pl
}

check for

updates

Citation: Ilska, M.; Kołodziej-Zaleska,

A.; Brandt-Salmeri, A.; Preis, H.;

Lobel, M. Pandemic Stress and Its

Correlates among Pregnant Women

during the Second Wave of

COVID-19 in Poland. Int. J. Environ.

Res. Public Health 2021, 18, 11140.

https://doi.org/10.3390/

ijerph182111140

Academic Editor: Francesca Agostini

Received: 12 September 2021

Accepted: 19 October 2021

Published: 23 October 2021

Publisher's Note: MDPI stays neutral with regard to jurisdictional claims in published maps and institutional affiliations.

Copyright: (C) 2021 by the authors Licensee MDPI, Basel, Switzerland. This article is an open access article distributed under the terms and conditions of the Creative Commons Attribution (CC BY) license (https:// creativecommons.org/licenses/by/ $4.0 /)$
Abstract: Background: The ongoing COVID-19 pandemic has created numerous stressful conditions, especially for vulnerable populations such as pregnant women. Pandemic-related pregnancy stress consists of two dimensions: stress associated with feeling unprepared for birth due to the pandemic (Preparedness Stress), and stress related to fears of perinatal COVID-19 infection (Perinatal Infection Stress). The purpose of our study was to elucidate the association between various factorssociodemographic, obstetric, pandemic-related, and situational—and pandemic stress in its two dimensions during the second wave of the COVID-19 pandemic in Polish pregnant women. Methods: A cross-sectional study with a total of 1119 pregnant women recruited during the second wave of the COVID-19 pandemic in Poland (between November 2020 and January 2021). Participants were recruited via social media to complete an online study questionnaire that included sociodemographic, obstetric, situational, and COVID-19 pandemic factors, as well as the Pandemic-Related Pregnancy Stress Scale (PREPS). Results: Nearly 38.5\% of participants reported high Preparedness Stress; $26 \%$ reported high Perinatal Infection Stress. Multivariate analyses indicated that lack of COVID-19 diagnosis, higher compliance with safety rules and restrictions, and limited access to outdoor space were independently associated with moderate to severe levels of Infection Stress. Current emotional or psychiatric problems, nulliparity, limited access to outdoor space, and alterations to obstetric visits were independently associated with moderate to severe Preparedness Stress. Conclusion: Study findings suggest that particular attention should be focused on the groups of pregnant women who are most vulnerable to pandemic-related stress and therefore may be more prone to adverse outcomes associated with prenatal stress.

Keywords: pregnancy; COVID-19; pandemic stress; correlates of stress; infection; preparedness

\section{Introduction}

The 2019 coronavirus disease (COVID-19) pandemic is a global health threat, and by far the largest outbreak of an infectious illness in modern history. The COVID-19 pandemic constitutes a significant source of distress for all people but may be particularly stressful for vulnerable groups [1]. Pregnant women are a high-risk population due to the potential dual impact on mother and fetus [2]. Pregnancy is a particularly critical period for women's mental health [3,4]. Depression and anxiety are some of the most prevalent pregnancy morbidities that have increased since the start of the COVID-19 pandemic [5-7]. Tomfohr-Madsen et al. [5] observed higher anxiety prevalence in pregnant women, which is potentially linked to exposure to pandemic chronic stressors and ongoing uncertainty. These authors point out that rates of antenatal depression and anxiety are significantly elevated during the COVID-19 pandemic compared to historical pre-pandemic norms, for example [8]. Other reports on the mental health of pregnant women during the pandemic confirm these trends. Researchers highlight the prevalence of anxiety symptoms $[2,9,10]$, severe pandemic stress $[9,11,12]$, and depression $[2,13,14]$ and also indicate that expectant 
and postpartum women have higher levels of anxiety and depression compared to similar cohorts assessed before the outbreak [15-18]. Studies of the determinants of anxiety and depression in pregnancy conducted during the COVID-19 pandemic have confirmed the importance of risk factors described previously as well as stressors related to pandemic circumstances $[19,20]$.

The COVID-19 pandemic is a danger to reproductive and perinatal health both directly, through infection itself, and indirectly, as a consequence of changes in health care, social policy, and social and economic circumstances [21]. The pandemic has introduced widespread chronic fear of infection and, in pregnant women, fear for the health of the fetus in the face of the spreading virus [11,22]. Pandemic stress as a consequence of these circumstances includes infection stress and stress related to preparing for childbirth [22]. Previous studies indicate that prenatal stress (including pandemic stress) and fear of childbirth are factors that may disrupt preparation for delivery and the course of the delivery itself and increase the likelihood of adverse birth outcomes including low birth weight and preterm delivery [23-25]. Moreover, recent research indicates that pandemic-related stress is a powerful construct that can affect the mental health of pregnant women, including an increase in symptoms of depression and anxiety $[9,20]$.

A growing body of evidence confirms the harmful consequences of COVID-19 for perinatal physical and mental health. A review carried out by Chmielewska et al. [15] showed that global maternal and fetal outcomes have worsened during the COVID-19 pandemic, with an increase in maternal deaths, stillbirths, ruptured ectopic pregnancies, and maternal depression. Pregnant women are among those who are most worried and concerned about spreading or becoming infected by SARS-CoV-2 [26,27]. Numerous factors may have intensified the worries of pregnant women, including the diverse range of symptoms and complications caused by the disease, limited scientific knowledge about its impact on fetal well-being, confinement, changes in daily routine, transformations of social life, financial problems, and interruptions of prenatal care $[2,28]$.

The pandemic unfolded in a wave-like manner. The outbreak of COVID-19 in Poland began at the end of March 2020 and reached its first peak during March and April 2020, with few infections and a small number of deaths. The first lockdown was introduced at this time as a preventive measure, which limited the possibility of movement, medical care (canceled or rescheduled medical appointments, introduction of telephone consultations), and the functioning of maternity wards and delivery rooms (suspension of appointments, births without a companion) $[29,30]$. The following months saw a slow return to normalcy, along with the re-opening of the economy, and a gradual lifting of restrictions in maternity care (e.g., accompanied births resumed, and a less restrictive protocol was adopted for the treatment of mothers infected with the virus).

The second wave of the pandemic in Poland, which started in November 2020 and lasted until January 2021, differed from the first in many respects. A sharp increase was observed in incidence of the coronavirus, with numerous deaths and hospitalizations of people suffering from severe COVID-19. A second lockdown was introduced along with shutdown of the economy, schools, and the return of restrictions relating to travel [31]. Constraints in medical care were reintroduced, including maternity care (suspension of accompanied labor, uncertainty about place of delivery, and total ban on hospital visitors). The second wave was also accompanied by changes in the public mood. Although the second wave was objectively more threatening than the first, there was less adherence to preventive measures. Research conducted by Chodkiewicz and colleagues [32] suggests that after initial mobilization in the first wave, stress became chronic and resilience mechanisms were increasingly ineffective, leading to psychological burnout. Additional studies have documented fatigue, burnout, loneliness, and a rise in anxiety, depression, and post-traumatic stress disorder [33-36].

Therefore, the aim of this study was to investigate the magnitude of pandemic stress in pregnant women during the second wave of the pandemic in Poland and identify its sociodemographic, obstetric, and situational correlates, including pandemic conditions. 


\section{Materials and Methods}

From November 2020 to January 2021, we recruited a sample of 1119 pregnant women through social media (i.e., Facebook, pregnancy and birth forums, the Polish Childbirth with Dignity Foundation). A cross-sectional study design with non-random sampling was used. Research assistants posted study advertisements on pregnancy-related social media that directed women to a link with the study questionnaire. The online questionnaire was completed through LimeSurvey, an online survey system. Inclusion criteria were Polish speaking women over 18 years of age who were pregnant during completion of the survey. The research procedure was approved by the Ethics Committee of Silesian University in Katowice (KEUS.43/05.2020).

\subsection{Methods}

COVID-19-related stress. The Pandemic-Related Pregnancy Stress Scale (PREPS [22]; Polish adaptation [11]) is a novel instrument that assesses prenatal stress during the pandemic. The PREPS has been translated into several languages and has been found to have good psychometric properties in different populations $[12,19,20]$. The PREPS includes a subscale that assesses stress related to preparation for birth and the postpartum period due to the pandemic (PREPS-Preparedness; PREPS-PS) and a second subscale that assesses stress involving concerns about infection of oneself or one's fetus/baby (PREPS-Infection; PREPS-IS). Both scales were internally consistent (PREPS-PS $\alpha=0.83$; PREPS-IS $\alpha=0.79$ ). A third PREPS subscale assessing positive appraisal was not pertinent to this study and therefore not used. Scores for each PREPS scale are calculated as mean item response on a scale from $1=$ Very little to $5=$ Very much.

Sociodemographic characteristics included maternal age (coded younger $<35 /$ older $\geq 35$ ), financial status (below average/average/above average), relationship status (some or no relationship/married or cohabiting), and level of education (high school/bachelor/postgrad).

Obstetric factors included unplanned pregnancy (no/yes), nullipara (no/yes), gestational age (in weeks and coded by trimester), high-risk pregnancy (no/yes/unsure), chronic medical conditions (no/yes), fertility treatments (no/yes), and length of time trying to conceive (up to a year/one year or more).

Situational predictors. Four factors were assessed with dichotomous questions (no/yes): experience of lifetime abuse, current emotional or psychiatric problems, major life events while pregnant, and feelings of discrimination or harassment because of race, sexuality, gender, or body size.

COVID-19-related conditions included loss of income because of COVID-19 (no/yes), COVID-19 tests in the last 2 months (no/yes), COVID-19 diagnosis in the last 2 months (no/yes), suspected COVID-19 infection without being medically diagnosed (no/yes/unsure), obstetric visit canceled or rescheduled because of COVID-19 (no/yes), telemedicine (no/ yes, but only during COVID/yes, in the past), access to outdoor space (yes, whenever I want/sometimes/rarely), and compliance with safety rules and restrictions (not much or a little/average or a lot).

\subsection{Statistical Analysis}

Mean differences in the continuous PREPS-IS and PREPS-PS stress score for women with different sociodemographic characteristics, obstetric factors, situational factors, and COVID-19-related conditions were evaluated using Independent Sample $t$-tests or ANOVA as appropriate. Following these steps, all variables that exhibited significant associations with the continuous PREPS-IS and PREPS-PS stress score in bivariate analyses were entered into a binary logistic regression model to calculate unadjusted and adjusted odds for high levels of PREPS-IS and PREPS-PS. Cut-off scores ( $\geq 4$ on the 1-5 response scale) were used to identify women experiencing moderate or severe levels of stress [37]. The criterion for statistical significance was $p<0.05$ for all analyses. 


\section{Results}

Participants were on average $29.79 \pm 3.81$ years old, with an average gestational age of 25 weeks ( $25.43 \pm 9.73)$. Almost half of the participants were nulliparas $(n=494,44.1 \%)$. Sixty-three women (5.6\%) reported being diagnosed with COVID-19 during pregnancy, and one-quarter ( $n=253,22.6 \%)$ thought they might have contracted COVID-19 during pregnancy but were not diagnosed. Other participant characteristics are displayed in Table 1.

Approximately a quarter $(26.1 \%)$ and more than a third (38.5\%) of the women scored a 4 or higher on the PREPS-IS subscale and PREPS-PS subscale, respectively, indicating high levels of COVID-19-related pregnancy stress.

Table 1. Sample characteristics and mean differences in PREPS-IS and PREPS-PS scale score based on sociodemographic characteristics, obstetric factors, and other predictors $(N=1119)$.

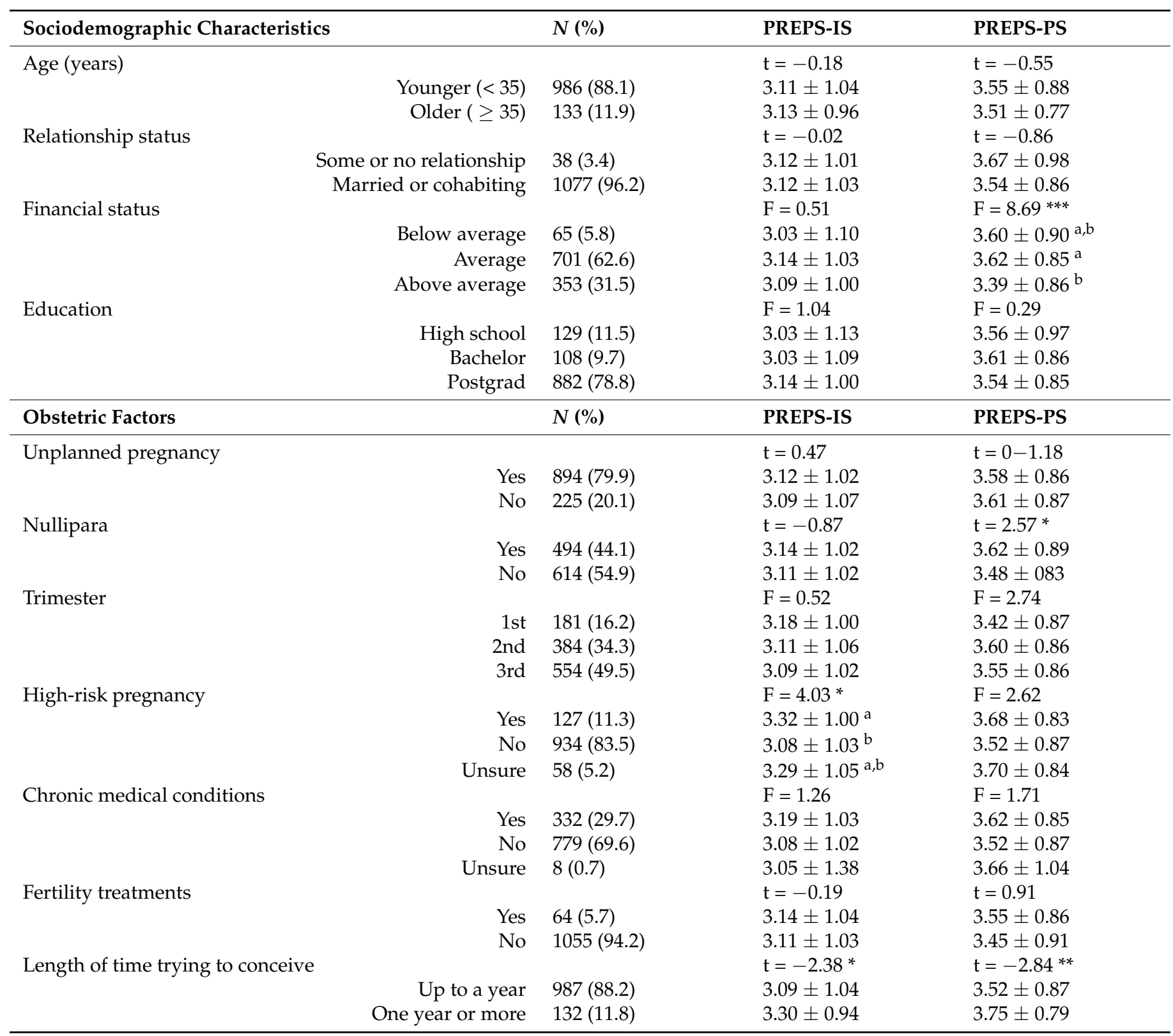


Table 1. Cont.

\begin{tabular}{lllll}
\hline Situational Predictors & & $N \mathbf{( \% )}$ & PREPS-IS & PREPS-PS \\
\hline Lifetime abuse & & & $\mathrm{t}=-0.99$ & $\mathrm{t}=-0.25$ \\
& Yes & $59(5.3)$ & $2.98 \pm 1.05$ & $3.52 \pm 0.89$ \\
& No & $1060(94.7)$ & $3.12 \pm 1.03$ & $3.55 \pm 0.86$ \\
Current emotional or psychiatric problems & & & $\mathrm{t}=2.08^{*}$ & $\mathrm{t}=4.11^{* * *}$ \\
& Yes & $194(10.4)$ & $3.25 \pm 1.01$ & $3.78 \pm 0.81$ \\
Major life event while pregnant & No & $925(89.6)$ & $3.09 \pm 1.03$ & $3.50 \pm 0.87$ \\
& & & $\mathrm{t}=0.62$ & $\mathrm{t}=2.82^{* *}$ \\
Felt discriminated against & Yes & $282(25.2)$ & $3.15 \pm 1.03$ & $3.67 \pm 0.81$ \\
& No & $837(74.8)$ & $3.10 \pm 1.03$ & $3.51 \pm 0.88$ \\
& & & $\mathrm{t}=2.03^{*}$ & $\mathrm{t}=3.73^{* * *}$ \\
& Yes $53(4.7)$ & $3.38 \pm 0.96$ & $3.98 \pm 0.74$ \\
& No & $1066(95.3)$ & $3.10 \pm 1.03$ & $3.53 \pm 0.86$ \\
\hline
\end{tabular}

Note: ${ }^{*} p<0.05 ;{ }^{* *} p<0.01 ;{ }^{* * *} p<0.001$. Means with different superscripts are significantly different at $p<0.05$ in a post hoc Scheffé test.

We investigated the association of PREPS factors with sociodemographic variables (age, relationship status, financial status, education), obstetric characteristics (unplanned pregnancy, nullipara, trimester, high-risk pregnancy, chronic medical conditions, fertility treatment, length of time trying to conceive), and situational factors (lifetime abuse, current emotional or psychiatric problems, major life event while pregnant, discrimination) (Table 1). We also examined associations with COVID-19-related conditions (income lost, COVID-19 test, diagnosis and perceived risk of COVID-19, prenatal care appointment alteration, telemedicine during COVID-19, access to outdoor space, safety rule restrictions) (Table 2).

Table 2. Sample characteristics and mean differences in PREPS-IS and PREPS-PS scale score based on COVID-19-related conditions $(N=1119)$.

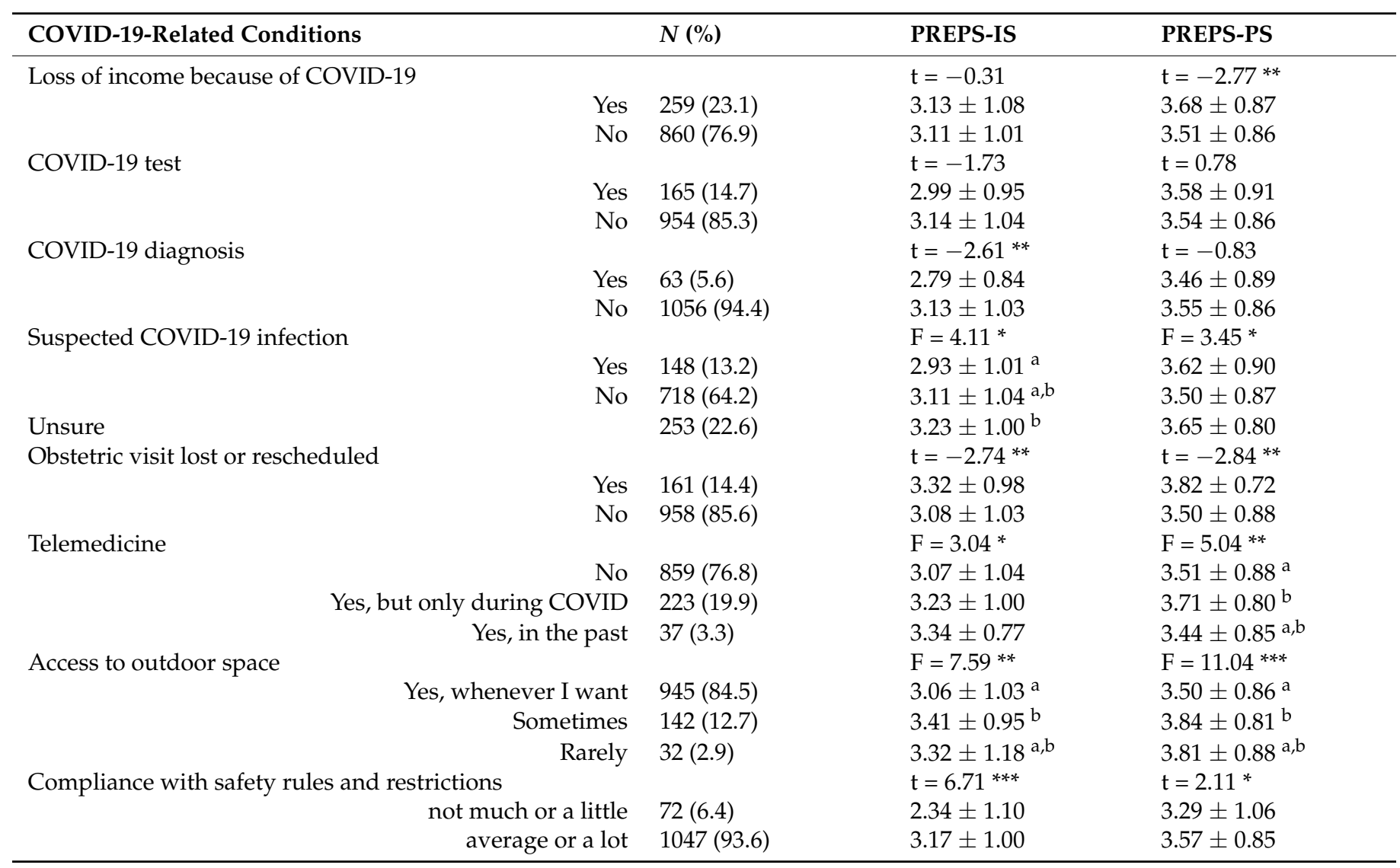

Note: ${ }^{*} p<0.05 ;{ }^{* *} p<0.01 ;{ }^{* * *} p<0.001$; Means with different superscripts are significantly different at $p<0.05$ in a post hoc Scheffé test. 
In the bivariate analyses, PREPS-IS was related to some of the obstetric factors, namely, high-risk pregnancy and length of time trying to conceive. PREPS-IS was also associated with current emotional or psychiatric problems and discrimination (see Table 1). As shown in Table 2, PREPS-IS was also associated with all but one of the COVID-19-related variables. The omnibus F-test was significant for telemedicine during pregnancy; however, the post hoc analysis showed no significant differences.

PREPS-PS was associated with financial status, nullipara, and length of time trying to conceive. PREPS-PS was also related to current emotional or psychiatric problems, major life events during pregnancy, and discrimination (see Table 1). As shown in Table 2, PREPS-PS was also associated with all but one of the COVID-19-related variables (see Table 2). The omnibus F-test was significant for suspected COVID-19 infection; however, the post hoc analysis showed no significant differences. Two logistic regression analyses were carried out to calculate the adjusted odds ratio (AOR) for those who reported the highest level of PREPS-IS and PREPS-PS. As shown in Table 3, the model predicting high levels of Perinatal Infection Stress incorporated variables that exhibited significant bivariate associations with a continuous PREPS-IS score. This regression model predicted $4 \%$ of the variance in PREPS-IS, with COVID-19 diagnosis (AOR 4.02, $p<0.01$ ), compliance with the safety rules and restrictions (AOR 3.05, $p<0.01$ ), and limited access to outdoor space (AOR $1.49, p<0.05)$, uniquely increasing the odds of high perinatal infection stress.

Table 3. Binary multivariate logistic regression predicting high levels of Infection Stress-PREPS-IS $(N=1119)$.

\begin{tabular}{|c|c|c|}
\hline & \multicolumn{2}{|c|}{ PREPS-IS } \\
\hline & AOR & $95 \% \mathrm{CI}$ \\
\hline \multicolumn{3}{|l|}{ Obstetric factors } \\
\hline High-risk $^{+}$ & 1.3 & $0.87,1.96$ \\
\hline Length of time trying to conceive & 1.09 & $0.72,1.65$ \\
\hline \multicolumn{3}{|l|}{ Situational factors } \\
\hline Emotional or psychiatric problems & 1.15 & $0.81,1.64$ \\
\hline Discrimination & 1.14 & $0.62,2.11$ \\
\hline \multicolumn{3}{|l|}{ COVID-19-related factors } \\
\hline No COVID diagnosis & $4.02 * *$ & $1.69,9.56$ \\
\hline Perceived risk of having had COVID-19 ${ }^{\dagger}$ & 1.06 & $0.79,1.41$ \\
\hline Appointment altered & 1.35 & $0.91,1.99$ \\
\hline Telemedicine obstetrician ${ }^{\dagger}$ & 1.19 & $0.84,1.67$ \\
\hline Limited access to outdoor space ${ }^{\dagger}$ & $1.49 *$ & $1.04,2.1$ \\
\hline Compliance with safety rules and restrictions & $3.05^{* *}$ & $1.44,6.48$ \\
\hline
\end{tabular}

${ }^{*} p<0.05,{ }^{* *} p<0.01$. AOR-Adjusted Odds Ratio; CI-Confidence Interval. ${ }^{\dagger}$ Women who reported being high-risk and those who were unsure were grouped together. Women who reported perceived risk of having COVID-19 and those who were unsure were grouped together. Women who reported no telemedicine obstetrician during COVID-19 and those who reported it before the pandemic were grouped together. Women who reported sometimes or rarely having access to outdoor space were grouped together.

As shown in Table 4, the model predicting high levels of Preparedness Stress incorporated variables that exhibited significant bivariate associations with the continuous PREPS-PS score. The regression model included sociodemographic, obstetric, situational, and COVID-19-related variables, which predicted $8 \%$ of the variance in PREPS-PS, with nulliparity (AOR 1.51, $p<0.05$ ), current emotional or psychiatric problems (AOR 1.52, $p<0.05$ ), income lost because of COVID-19 (AOR 1.36, $p<0.05$ ), obstetric visits canceled or rescheduled (AOR 1.52, $p<0.05$ ), and limited access to outdoor space (AOR 2.21, $p<0.001$ ) uniquely increasing the odds of high perinatal Preparedness Stress. 
Table 4. Binary multivariate logistic regression predicting high levels of Preparedness Stress $(N=1119)$.

\begin{tabular}{|c|c|c|}
\hline & \multicolumn{2}{|c|}{ PREPS-PS } \\
\hline & AOR & $95 \% \mathrm{CI}$ \\
\hline \multicolumn{3}{|l|}{ Sociodemographic factors } \\
\hline Financial status $^{\dagger}$ & 0.93 & $0.54,1.62$ \\
\hline \multicolumn{3}{|l|}{ Obstetric factors } \\
\hline Nulliparity & $1.51^{* *}$ & $1.17,1.95$ \\
\hline Length of time trying to conceive & 1.21 & $0.82,1.78$ \\
\hline \multicolumn{3}{|l|}{ Situational factors } \\
\hline Discrimination & 1.63 & $0.91,2.94$ \\
\hline Emotional or psychiatric problems & $1.52 *$ & $1.09,2.14$ \\
\hline Major life event & 1.12 & $0.84,1.51$ \\
\hline \multicolumn{3}{|l|}{ COVID-19-related factors } \\
\hline Income lost & $1.36^{*}$ & $1.01,1.83$ \\
\hline Perceived risk of having had COVID-19 ${ }^{+}$ & 1.17 & $0.90,1.52$ \\
\hline Appointment altered & $1.52 *$ & $1.06,2.17$ \\
\hline Telemedicine obstetrician ${ }^{\dagger}$ & 1.28 & $0.93,1.76$ \\
\hline Limited access to outdoor space $^{\dagger}$ & $2.21^{* * *}$ & $1.57,3.11$ \\
\hline \multirow[t]{2}{*}{ Compliance with the safety rules and restrictions } & 1.12 & $0.67,1.88$ \\
\hline & $R^{2}=0$ & \\
\hline
\end{tabular}

${ }^{*} p<0.05,{ }^{* *} p<0.01,{ }^{* * *} p<0.001$. AOR-Adjusted Odds Ratio; CI-Confidence Interval. ${ }^{\dagger}$ Women who reported below average or average financial status were grouped together. Women who reported perceived risk of having COVID-19 and those who were unsure were grouped together. Women who reported no telemedicine obstetrician during COVID-19 and those who reported it before the pandemic were grouped together. Women who reported sometimes or rarely having access to outdoor space were grouped together.

\section{Discussion}

The COVID-19 pandemic has pervasive consequences for society including death, economic uncertainty, and strained health care systems. Moreover, the pandemic has triggered a wide variety of psychiatric problems, including anxiety and depression, especially in sensitive populations such as pregnant women $[5,38,39]$. Additional factors related to pandemic conditions and resulting pandemic stress also threaten maternal mental health.

The current study identified the magnitude and correlates of pandemic-related pregnancy stress during the second wave of COVID-19 in Poland. Nearly a third of pregnant women experienced elevated levels of stress related to feeling unprepared for birth or being worried about perinatal infection. The present research is consistent with other studies carried out in Poland, including those devoted to the COVID-19 pandemic's negative impact on various dimensions of mental health in pregnant women [40,41].

Sociodemographic, obstetric, and situational factors including pandemic conditions were important correlates of this stress. Most of these factors were specific to one of the two dimensions of pandemic-related prenatal stress, but some-in particular, the pandemic conditions - were associated with both stress about perinatal infection and about feeling unprepared for birth. These common pandemic-related correlates of stress included uncertainty about being ill with COVID-19, limited access to outdoor space, cancelation or postponement of obstetric appointments, and compliance with safety rules and restrictions. Similarly, trying to conceive for more than a year, as well as feeling discriminated against and experiencing emotional and psychiatric problems, were associated with higher levels of pandemic stress of both types.

Although a more limited number of factors distinguished women who were experiencing moderate or severe levels of stress, pandemic conditions were the only factors associated with moderate or severe infection stress; similarly, pandemic conditions constituted a majority of the factors associated with moderate or severe birth preparation stress. Notably, limited access to outdoor space was the only pandemic-related factor significantly associated with high levels of both types of stress. These results parallel those of comparable studies conducted in the US, Germany, and Switzerland during the first wave of the pandemic $[9,12]$. It is instructive that alterations of obstetric appointments were 
associated with maternal stress, for the pandemic disrupted normal ways of preparing for childbirth, including the regularity of obstetric appointments according to an established schedule, the availability of medical care in situations that threaten the health of the mother or baby, and participation in antenatal classes. Research from the first wave of the pandemic in Poland also showed that prenatal care appointment cancelation or rescheduling was associated with pandemic stress in pregnant women [10]. The availability, stability, and continuity of medical care during pregnancy are crucial for a sense of security in pregnancy. The pandemic has highlighted pre-existing challenges related to the delivery of standard, high quality, and accessible prenatal care in Poland [42,43]. These findings reinforce the urgent need to prioritize safe, accessible, and equitable maternity care within the strategic response to this pandemic, and in future health crises.

Study findings also suggest that during the pandemic, close attention should be focused on particular groups of pregnant women, similarly identified by prior research as vulnerable to high maternal stress $[12,23,37]$ : women pregnant for the first time, those with a high-risk pregnancy, women who have been trying to conceive for a long time, women who feel discriminated against for various reasons, those who have experienced major life events during pregnancy, and those with other emotional and psychiatric difficulties. These groups experience a higher level of pandemic-related pregnancy stress and therefore may be more prone to complications associated with prenatal stress, including preterm birth, low birthweight, and other outcomes that are well-recognized consequences of high maternal stress during pregnancy [44,45]. For these women, early intervention and the provision of psychological support tailored to their needs may also prevent the development or aggravation of psychopathology.

A higher level of pandemic-related pregnancy stress was also associated with women's sense of uncertainty around contracting COVID-19. It should be noted that during the second wave of the pandemic in Poland, there was very limited availability of tests, and thus individuals had little knowledge about their possible SARS-CoV-2 infection. A small percentage of women were tested for SARS-CoV-2, and the percentage of pregnant women who knew they had already had COVID-19 was also low. However, almost one-third suspected that they had contracted COVID-19. These women experienced higher pandemic stress of both types: related to infection fear and to lack of preparation for birth. Thus, increasing access to testing would likely help alleviate maternal stress. Research reports that appeared during this time showed that having COVID-19 provides basic immunity against recurrence and reduces the risk of serious complications in the event of another infection $[46,47]$. This message was widespread in the media and online and is the likely reason why women who reported a prior infection experienced lower stress. Moreover, a stress exposure mechanism may also be at play, reflecting confidence about the ability to manage stress related to the virus among those who were ill and recovered [48].

Interestingly, we found that greater compliance with safety rules and restrictions was associated with higher pandemic-related stress. In other studies, higher anxiety related to COVID-19 has been associated with a tendency to comply with safety rules during the pandemic [49], or with undertaking various protective behaviors [50]. The association that we uncovered between compliance and stress may thus reflect greater cautiousness among pregnant women harboring fears and concerns about infection and birth. However, it is also possible that vigilance with recommended activities designed for safety and health may reinforce or activate fears related to the pandemic and thus intensify pandemicrelated stress $[48,51]$. More in-depth, longitudinal research may be able to untangle these possibilities and distinguish levels of compliance that are healthy and protective from hypervigilance or extreme behaviors that suggest underlying pathology.

\subsection{Implications for Practice and/or Policy}

Given the pandemic context and the vulnerability of pregnant women, it is imperative to recognize distress signals in order to prevent the development or aggravation of psychopathology. Such observations should be made continuously, at various stages of the 
pandemic, making it possible to understand the dynamics of these changes and respond with adequate interventions, tailoring support to specific needs.

\subsection{Limitations and Strengths}

One of the limitations of this study is the recruitment method, which excluded women who had no access to the internet or social media. As a consequence, the results may not be widely generalizable. Another limitation is the cross-sectional nature of the research, which prevents us from ascertaining whether study variables are predictors or consequences of pandemic-related pregnancy stress. Some may have bidirectional associations with stress. Furthermore, because data were collected exclusively by self-report, we cannot confirm their accuracy.

Another study limitation stems from the online recruitment method, which can introduce bias into the sample. During the pandemic, conducting face-to-face research was difficult or impossible. Future research should consider interview-based assessments and medical chart data to replicate and extend these findings.

Nevertheless, this research also possesses a number of strengths. The use of a wellvalidated instrument to assess pandemic-related stress and its correlates in a large sample of women pregnant during a time of national emergency provides critical information that can be used to protect the health of childbearing women and their offspring, and these data offer a foundation to examine longer-term effects of the pandemic on this vulnerable population.

\section{Conclusions}

The COVID-19 pandemic and its multiple waves have created numerous conditions that generate stress for pregnant women related to the possibility of infection of themselves or their baby, and stress related to their preparation for childbirth. This study contributes to our understanding of pregnant women's experiences during an especially dangerous period of the COVID-19 pandemic in Poland and extends the literature on stress during pregnancy. Findings highlight which women are at the greatest risk of elevated stress and offer insight into how this stress might be reduced.

Author Contributions: Conceptualization, M.I., A.B.-S., A.K.-Z., H.P. and M.L.; Data curation, M.I., A.B.-S. and A.K.-Z.; Formal analysis, M.I., A.B.-S. and A.K.-Z.; Investigation M.I., A.B.-S. and A.K.-Z.; Methodology M.I., A.B.-S., A.K.-Z., H.P. and M.L.; Project administration M.I.; Resources M.I., A.B.-S. and A.K.-Z.; Software M.I., A.B.-S. and A.K.-Z.; Visualization M.I., Writing-review and editing A.B.-S., A.K.-Z., M.I., A.B.-S., A.K.-Z., H.P. and M.L., Supervision H.P. and M.L. All authors have read and agreed to the published version of the manuscript.

Funding: This research received no external funding.

Institutional Review Board Statement: The study was conducted according to the guidelines of the Declaration of Helsinki, and the research procedure was approved by the Ethics Committee of Silesian University in Katowice (KEUS.43/05.2020).

Informed Consent Statement: Informed consent was obtained from all subjects involved in the study.

Data Availability Statement: The datasets used and/or analyzed during the current study are available from the corresponding author upon request.

Acknowledgments: We would like to thank the excellent research assistants who helped in carrying out this project: Joanna Bojdys, Marta Buchenfeld, Małgorzata Gabryś, Emilia Maciak, Adrianna Małek, Dominika Serzysko, Magdalena Twardowska. Special thanks to Fundacja "Rodzić po Ludzku”, Jagoda Sikora, Agnieszka Stążka-Gawrysiak, Alicja Kost, Magdalena Komsta, Dawid Serafin for their invaluable support in conducting this research.

Conflicts of Interest: The authors declare no conflict of interest. 


\section{References}

1. Pakpour, A.H.; Griffiths, M.D. The fear of COVID-19 and its role in preventive behaviors. J. Councurrent Disord. 2020, 2, 58-63.

2. López-Morales, H.; del Valle, M.V.; Canet-Juric, L.; Andrés, M.L.; Galli, J.I.; Poó, F.; Urquijo, S. Mental health of pregnant women during the COVID-19 pandemic: A longitudinal study. Psychiatry Res. 2021, 295, 113567. [CrossRef]

3. Darvill, R.; Skirton, H.; Farrand, P. Psychological factors that impact on women's experiences of first-time motherhood: A qualitative study of the transition. Midwifery 2010, 26, 357-366. [CrossRef]

4. Ilska, M.; Brandt-Salmeri, A.; Kołodziej-Zaleska, A. Effect of prenatal distress on subjective happiness in pregnant women: The role of prenatal attitudes towards maternity and ego-resiliency. Pers. Individ. Differ. 2020, 163, 110098. [CrossRef]

5. Tomfohr-Madsen, L.M.; Racine, N.; Giesbrecht, G.F.; Lebel, C.; Madigan, S. Depression and anxiety in pregnancy during COVID-19: A rapid review and meta-analysis. Psychiatry Res. 2021, 300, 113912. [CrossRef] [PubMed]

6. Underwood, L.; Waldie, K.; D’Souza, S.; Peterson, E.R.; Morton, S. A review of longitudinal studies on antenatal and postnatal depression. Arch. Women's Ment. Health 2016, 19, 711-720. [CrossRef] [PubMed]

7. Fawcett, E.J.; Fairbrother, N.; Cox, M.L.; White, I.; Fawcett, J.M. The Prevalence of Anxiety Disorders During Pregnancy and the Postpartum Period: A Multivariate Bayesian Meta-Analysis. J. Clin. Psychiatry 2019, 80, 18r12527. [CrossRef]

8. Dennis, C.-L.; Falah-Hassani, K.; Shiri, R. Prevalence of antenatal and postnatal anxiety: Systematic review and meta-analysis. Br. J. Psychiatry 2017, 210, 315-323. [CrossRef] [PubMed]

9. Preis, H.; Mahaffey, B.; Heiselman, C.; Lobel, M. Pandemic-related pregnancy stress and anxiety among women pregnant during the coronavirus disease 2019 pandemic. Am. J. Obstet. Gynecol. MFM 2020, 2, 100155. [CrossRef]

10. Ilska, M.; Brandt-Salmeri, A.; Kołodziej-Zaleska, A.; Preis, H.; Rehbein, E.; Lobel, M. Anxiety in Pregnant Women during the First Wave of the COVID-19 Pandemic in Poland. Unpublished Manuscript.

11. Ilska, M.; Kołodziej-Zaleska, A.; Brandt-Salmeri, A.; Preis, H.; Lobel, M. Pandemic-related pregnancy stress assessmentPsychometric properties of the Polish PREPS and its relationship with childbirth fear. Midwifery 2021, 96, 102940. [CrossRef]

12. Schaal, N.K.; La Marca-Ghaemmaghami, P.; Preis, H.; Mahaffey, B.; Lobel, M.; Castro, R.A. The German version of the pandemicrelated pregnancy stress scale: A validation study. Eur. J. Obstet. Gynecol. Reprod. Biol. 2021, 256, 40-45. [CrossRef]

13. Salehi, L.; Rahimzadeh, M.; Molaei, E.; Zaheri, H.; Esmaelzadeh-Saeieh, S. The relationship among fear and anxiety of COVID-19, pregnancy experience, and mental health disorder in pregnant women: A structural equation model. Brain Behav. 2020, 10, e01835. [CrossRef] [PubMed]

14. Perzow, S.E.; Hennessey, E.-M.P.; Hoffman, M.C.; Grote, N.K.; Davis, E.P.; Hankin, B.L. Mental health of pregnant and postpartum women in response to the COVID-19 pandemic. J. Affect. Disord. Rep. 2021, 4, 100123. [CrossRef] [PubMed]

15. Chmielewska, B.; Barratt, I.; Townsend, R.; Kalafat, E.; van der Meulen, J.; Gurol-Urganci, I.; O’Brien, P.; Morris, E.; Draycott, T.; Thangaratinam, S.; et al. Effects of the COVID-19 pandemic on maternal and perinatal outcomes: A systematic review and meta-analysis. Lancet Glob. Health 2021, 9, e759-e772. [CrossRef]

16. Ceulemans, M.; Hompes, T.; Foulon, V. Mental health status of pregnant and breastfeeding women during the COVID-19 pandemic: A call for action. Int. J. Gynecol. Obstet. 2020, 151, 146-147. [CrossRef]

17. Lebel, C.; MacKinnon, A.; Bagshawe, M.; Tomfohr-Madsen, L.; Giesbrecht, G. Elevated depression and anxiety symptoms among pregnant individuals during the COVID-19 pandemic. J. Affect. Disord. 2020, 277, 5-13. [CrossRef]

18. Liu, X.; Chen, M.; Wang, Y.; Sun, L.; Zhang, J.; Shi, Y.; Wang, J.; Zhang, H.; Sun, G.; Baker, P.N.; et al. Prenatal anxiety and obstetric decisions among pregnant women in Wuhan and Chongqing during the COVID-19 outbreak: A cross-sectional study. BJOG Int. J. Obstet. Gynaecol. 2020, 127, 1229-1240. [CrossRef]

19. Colli, C.; Penengo, C.; Garzitto, M.; Driul, L.; Sala, A.; Degano, M.; Preis, H.; Lobel, M.; Balestrieri, M. Prenatal Stress and Psychiatric Symptoms During Early Phases of the COVID-19 Pandemic in Italy. Int. J. Women's Health 2021, 13, 653-662. [CrossRef]

20. Yirmiya, K.; Yakirevich-Amir, N.; Preis, H.; Lotan, A.; Atzil, S.; Reuveni, I. Women's Depressive Symptoms during the COVID-19 Pandemic: The Role of Pregnancy. Int. J. Environ. Res. Public Health 2021, 18, 4298. [CrossRef] [PubMed]

21. Kotlar, B.; Gerson, E.; Petrillo, S.; Langer, A.; Tiemeier, H. The impact of the COVID-19 pandemic on maternal and perinatal health: A scoping review. Reprod. Health 2021, 18, 10. [CrossRef]

22. Preis, H.; Mahaffey, B.; Lobel, M. Psychometric properties of the Pandemic-Related Pregnancy Stress Scale (PREPS). J. Psychosom. Obstet. Gynecol. 2020, 41, 191-197. [CrossRef]

23. Ibrahim, S.M.; Lobel, M. Conceptualization, measurement, and effects of pregnancy-specific stress: Review of research using the original and revised Prenatal Distress Questionnaire. J. Behav. Med. 2020, 43, 16-33. [CrossRef]

24. Molgora, S.; Accordini, M. Motherhood in the Time of Coronavirus: The Impact of the Pandemic Emergency on Expectant and Postpartum Women's Psychological Well-Being. Front. Psychol. 2020, 11, 567155. [CrossRef] [PubMed]

25. Preis, H.; Mahaffey, B.; Lobel, M. The role of pandemic-related pregnancy stress in preference for community birth during the beginning of the COVID-19 pandemic in the United States. Birth 2021, 48, 242-250. [CrossRef]

26. Brooks, S.; Weston, D.; Greenberg, N. Psychological impact of infectious disease outbreaks on pregnant women: Rapid evidence review. Public Health 2020, 189, 26-36. [CrossRef] [PubMed]

27. Mirzadeh, M.; Khedmat, L. Pregnant women in the exposure to COVID-19 infection outbreak: The unseen risk factors and preventive healthcare patterns. J. Matern. Neonatal Med. 2020, 2020, 1749257. [CrossRef] [PubMed]

28. Mortazavi, F.; Agah, J. Childbirth Fear and Associated Factors in a Sample of Pregnant Iranian Women. Oman Med. J. 2018, 33, 497-505. [CrossRef] [PubMed] 
29. Zimmer, M. Rekomendowana Ścieżka Postępowania dla Kobiet w Ciąży COVID-19 | PTGiP. Available online: https://www. ptgin.pl/rekomendowana-sciezka-postepowania-dla-kobiet-w-ciazy-covid-19 (accessed on 4 October 2021).

30. Zimmer, M.; Czajkowski, K. Stanowisko PTGiP i Konsultanta Krajowego w Sprawie Porodów Rodzinnych w Obliczu COVID-19 I PTGiP. Available online: https://www.ptgin.pl/stanowisko-ptgip-i-konsultanta-krajowego-w-sprawie-porodow-rodzinnychw-obliczu-covid-19 (accessed on 4 October 2021).

31. The Council of Ministers. Regarding the Establishment of Certain Restrictions and Prohibitions in Relation to the Onset of an Epidemic. Polish J. Laws 2020, 2020, 1758.

32. Chodkiewicz, J.; Miniszewska, J.; Krajewska, E.; Biliński, P. Mental Health during the Second Wave of the COVID-19 PandemicPolish Studies. Int. J. Environ. Res. Public Health 2021, 18, 3423. [CrossRef]

33. Morgul, E.; Bener, A.; Atak, M.; Akyel, S.; Aktaş, S.; Bhugra, D.; Ventriglio, A.; Jordan, T.R. COVID-19 pandemic and psychological fatigue in Turkey. Int. J. Soc. Psychiatry 2020, 67, 128-135. [CrossRef]

34. Torales, J.; O'Higgins, M.; Castaldelli-Maia, J.M.; Ventriglio, A. The outbreak of COVID-19 coronavirus and its impact on global mental health. Int. J. Soc. Psychiatry 2020, 66, 317-320. [CrossRef]

35. Bartoszek, A.; Walkowiak, D.; Bartoszek, A.; Kardas, G. Mental Well-Being (Depression, Loneliness, Insomnia, Daily Life Fatigue) during COVID-19 Related Home-Confinement-A Study from Poland. Int. J. Environ. Res. Public Health 2020, 17, 7417. [CrossRef] [PubMed]

36. Rajkumar, R.P. COVID-19 and mental health: A review of the existing literature. Asian J. Psychiatry 2020, 52, 102066. [CrossRef]

37. Preis, H.; Mahaffey, B.; Heiselman, C.; Lobel, M. Vulnerability and resilience to pandemic-related stress among U.S. women pregnant at the start of the COVID-19 pandemic. Soc. Sci. Med. 2020, 266, 113348. [CrossRef]

38. Hessami, K.; Romanelli, C.; Chiurazzi, M.; Cozzolino, M. COVID-19 pandemic and maternal mental health: A systematic review and meta-analysis. J. Matern. Neonatal Med. 2020, 1-8. [CrossRef] [PubMed]

39. Yan, H.; Ding, Y.; Guo, W. Mental Health of Pregnant and Postpartum Women During the Coronavirus Disease 2019 Pandemic: A Systematic Review and Meta-Analysis. Front. Psychol. 2020, 11, 617001. [CrossRef] [PubMed]

40. Mikolajkow, A.; Małyszczak, K. Stress level and general mental state in Polish pregnant women during COVID-19 pandemic. J. Reprod. Infant Psychol. 2021, 1-18. [CrossRef]

41. Nowacka, U.; Kozlowski, S.; Januszewski, M.; Sierdzinski, J.; Jakimiuk, A.; Issat, T. COVID-19 Pandemic-Related Anxiety in Pregnant Women. Int. J. Environ. Res. Public Health 2021, 18, 7221. [CrossRef]

42. Adamska-Sala, I.; Baranowska, B.; Doroszewska, A.; Piekarek, M.; Pietrusiewicz, J. Perinatal Care in Poland in the Light of Women's Experiences. 2018. Available online: www.rodzicpoludzku.pl (accessed on 19 October 2021).

43. Węrzynowska, M.; Doroszewska, A.; Witkiewicz, M.; Baranowska, B. Polish maternity services in times of crisis: In search of quality care for pregnant women and their babies. Health Care Women Int. 2020, 41, 1335-1348. [CrossRef]

44. Lobel, M.; DeVincent, C.J.; Kaminer, A.; Meyer, B.A. The impact of prenatal maternal stress and optimistic disposition on birth outcomes in medically high-risk women. Health Psychol. 2000, 19, 544-553. [CrossRef]

45. Ding, X.; Liang, M.; Wu, Y.; Zhao, T.; Qu, G.; Zhang, J.; Zhang, H.; Han, T.; Ma, S.; Sun, Y. The impact of prenatal stressful life events on adverse birth outcomes: A systematic review and meta-analysis. J. Affect. Disord. 2021, 287, 406-416. [CrossRef] [PubMed]

46. Ripperger, T.J.; Uhrlaub, J.L.; Watanabe, M.; Wong, R.; Castaneda, Y.; Pizzato, H.A.; Thompson, M.R.; Bradshaw, C.; Weinkauf, C.C.; Bime, C.; et al. Orthogonal SARS-CoV-2 Serological Assays Enable Surveillance of Low-Prevalence Communities and Reveal Durable Humoral Immunity. Immunity 2020, 53, 925-933.e4. [CrossRef] [PubMed]

47. Chandrashekar, A.; Liu, J.; Martinot, A.J.; Mcmahan, K.; Mercado, N.B.; Peter, L.; Tostanoski, L.H.; Yu, J.; Maliga, Z.; Nekorchuk, M.; et al. SARS-CoV-2 infection protects against rechallenge in rhesus macaques. Science 2020, 369, 812-817. [CrossRef] [PubMed]

48. Clark, D.A.; Beck, A.T. Cognitive theory and therapy of anxiety and depression: Convergence with neurobiological findings. Trends Cogn. Sci. 2010, 14, 418-424. [CrossRef] [PubMed]

49. Kowalczuk, I.; Gębski, J. Impact of Fear of Contracting COVID-19 and Complying with the Rules of Isolation on Nutritional Behaviors of Polish Adults. Int. J. Environ. Res. Public Health 2021, 18, 1631. [CrossRef]

50. Tkhostov, A.; Rasskazova, E. Psychological Contents of Anxiety and the Prevention in an Infodemic Situation: Protection against Coronavirus or the "Vicious Circle" of Anxiety? Couns. Psychol. Psychother. 2020, 28, 70-89. [CrossRef]

51. Thwaites, R.; Freeston, M.H. Safety-Seeking Behaviours: Fact or Function? How Can We Clinically Differentiate Between Safety Behaviours and Adaptive Coping Strategies across Anxiety Disorders? Behav. Cogn. Psychother. 2005, 33, 177-188. [CrossRef] 